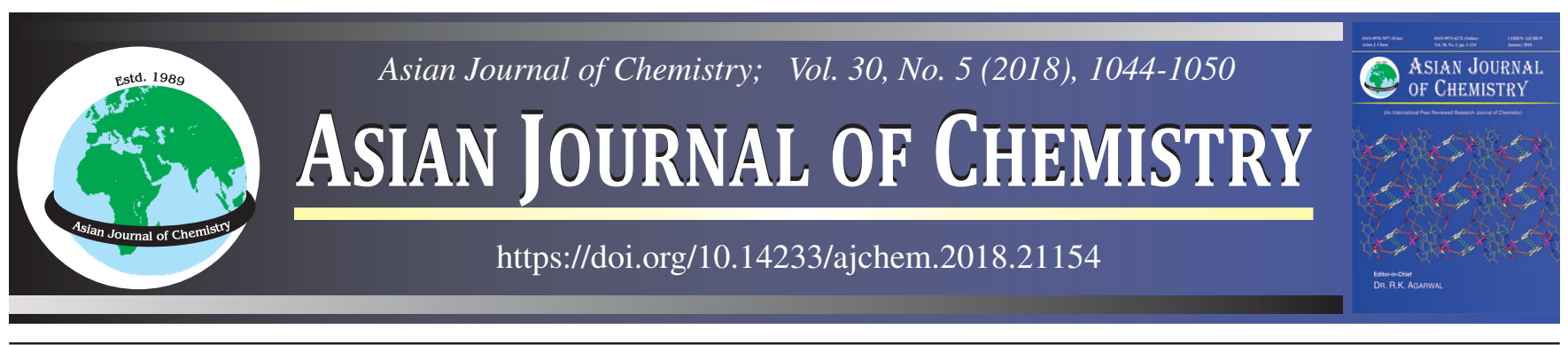

\title{
Synthesis of Zeolite Beta and Zeolite ZSM-5 from High Silica Raw \\ Kaolinite and Their Catalytic Etherification of Ethylene Glycol
}

\author{
Rasha S. RawajFeH and Hamdallah A. Hodali"
}

Department of Chemistry, Faculty of Science, The University of Jordan, Amman 11942, Jordan

*Corresponding author: E-mail: h-hodali@ju.edu.jo; hodali19@gmail.com

Received: 27 November 2017;

Accepted: 6 March 2018;

Published online: 29 March 2018;

AJC-18837

Pure phases of zeolites Beta and ZSM-5 were synthesized from high silica raw kaolinite. Both zeolites were characterized by XRD, XRF, SEM and $\mathrm{N}_{2}$ adsorption/desorption isotherms. The acid forms of zeolites (H-zeolite) were used in the catalytic etherification of ethylene glycol with benzyl alcohol and with $t$-butanol. In the reaction of ethylene glycol with benzyl alcohol, ethylene glycol monobenzyl ether was the only detected product over H-ZSM-5, while in case of H-zeolite Beta, ethylene glycol monobenzyl ether and ethylene glycol dibenzyl ether were detected. The highest yield of ethylene glycol monobenzyl ether (58\%) was obtained from H-ZSM-5 prepared from raw kaolinite.

Keywords: Zeolite Beta, Zeolite ZSM-5, Ethylene glycol, Ethylene glycol monobenzyl ether, Ethylene glycol mono-t-butyl ether.

ᄂ - - - - - - - - - - - - - - - - - - - - - - - - - - - - - - -

\section{INTRODUCTION}

Zeolites are crystalline microporous material with interconnected pore systems that form different channel structures. Aluminosilicate zeolites are built of $\mathrm{SiO}_{4}$ and $\mathrm{AlO}_{4}$ tetrahedral units shared with O-atoms. Zeolite Beta, with BEA structure, is a large pore zeolite with a three-dimensional 12-memberd ring channel system, while ZSM-5, with MFI structure, is a medium pore zeolite with a three-dimensional 10-membered ring channel system. Zeolite Beta was first synthesized from homogenous aluminosilicate hydrogel using tetraethylammonium hydroxide $(\mathrm{TEAOH})$ as a template [1]. Following that many preparative methods were reported using TEA ${ }^{+}$cation as a template [2-4]. Apart from using pure chemicals in zeolite synthesis, kaolinite clay $\left(\mathrm{Al}_{2} \mathrm{Si}_{2} \mathrm{O}_{5}(\mathrm{OH})_{4}\right)$ has been used for the synthesis of zeolite Beta, as a low-cost source of silicon and aluminum, abundant and friendly to the environment [5]. In these methods, purified kaolinite was converted to metakaolinite, acid-leached and then hydrothermally treated with TEAOH to give zeolite Beta. However, zeolite Beta produced by these methods was found contaminated with residual acid-leached metakaolinite [6,7].

On the other hand, zeolite ZSM-5 was first synthesized from pure chemicals using tetrapropylammonium hydroxide (TPAOH) as a template [8]. Following that many research groups used TPA salts with $\mathrm{TPA}^{+}$cation acting as a template [9-11]. Synthesis of zeolite ZSM-5 with different $\mathrm{SiO}_{2} / \mathrm{Al}_{2} \mathrm{O}_{3}$ molar ratio from purified kaolinite [12-15], or from high silica raw kaolinite $\left(\mathrm{SiO}_{2} /\right.$
$\mathrm{Al}_{2} \mathrm{O}_{3}$ ratio $=\sim 3$ ) was reported [16]. Zeolites obtained from kaolinite as mentioned in the above methods were impure and usually contaminated with unreacted metakaolinite or quartz. Recently, pure phase zeolite ZSM-5 was obtained from high silica raw kaolinite $\left(\mathrm{SiO}_{2} / \mathrm{Al}_{2} \mathrm{O}_{3}\right.$ molar ratio $\left.=\sim 4\right)$ [17]. In this work, the synthesis of zeolite Beta and zeolite ZSM-5 from high silica raw kaolinite is optimized to produce pure phase zeolites with good yield. The synthesized zeolites are used in the catalytic etherification of ethylene glycol with alcohols.

Catalytic etherification of alcohols over zeolites is of interest to many research groups. Dehydration of alcohols over zeolite catalysts to produce symmetric ethers, such as the dehydration of 1-pentanol [18], 1-hexanol [19] and 1-octanol [20], was extensively studied. Dehydration among two different alcohols to produce asymmetric ethers, such as dehydration of methanol with $t$-butanol [21], ethanol with $t$-butanol [22] and ethanol with 2-naphthol [23], was studied over zeolites. Dehydration of glycerol with benzyl alcohol $[24,25]$ and with $t$-butanol $[26,27]$ catalyzed by zeolites was reported to produced glycerol mono-, di- or trialkyl ethers. Both zeolite Beta and zeolite ZSM-5 were involved in most of the above catalytic etherification processes. To our best of knowledge, catalytic etherification of ethylene glycol with alcohols to produce ethylene glycol monoalkyl ethers (EGMEs) using zeolites has not been reported. This important class of $\beta$-hydroxy ethers [28-30] was commercially produced via catalytic alcoholysis of alkylene oxides [31,32] 
reductive cleavage of cyclic acetals or ketals in the presence of hydrogenation active catalyst [32-34] and the catalytic alkylation of diols with alkyl halide [35]. Etherification of ethylene glycol with 1-octene using heteropoly acid supported on clay was recently reported [36]. Dehydration reaction of ethylene glycol and 1-octanol was reported to occur over unimodal mesoporous silicate (MCM-41) modified with tin [37].

In this work, we report the liquid phase etherification of ethylene glycol with benzyl alcohol and with $t$-butanol over acid-activated zeolites (H-Beta and H-ZSM-5), prepared from raw kaolinite and from pure chemicals.

\section{EXPERIMENTAL}

Fumed silica with average particle size between $0.2-0.3 \mu \mathrm{m}$, sodium metasilicate nonahydrate (98\%), sodium aluminate (50-56 \% $\left.\mathrm{Al}_{2} \mathrm{O}_{3}, 40-45 \% \mathrm{Na}_{2} \mathrm{O}\right)$, anhydrous ethylene glycol ( 99.8 $\%)$ and ethylene glycol monobenzyl ether (EGMBE, $98 \%$ ) were purchased from Aldrich Chemicals. Tetraethylammonium hydroxide (TEAOH, $20 \mathrm{wt} \%$ in water), TEAOH (40 wt \% in water), tetrapropylammonium bromide (TPABr, 98\%), 2-methoxy ethanol and 1,5-pentanediol (98\%) were supplied by Acros Organics. Aluminum sulfate hexadecahydrate, 1-propanol (98 $\%)$, barium chloride dihydrate, dibenzyl ether (98\%) were purchased from Fluka, benzyl alcohol (99.8\%, Riedel-dehaen), $t$-butanol (99.5\%, Daejung), sodium sulfate anhydrous (99.5\%, Super Chem.), methanol (HPLC grade, Fulltime), ethylene glycol dibenzyl ether (EGDBE, $95 \%$ ) and ethylene glycol mono- $t$ butyl ether (EGMTE) were used as purchased. Deionized water was used throughout the work. Raw kaolinite was collected from Batn El-Ghoul area, south of Jordan.

$\mathrm{X}$-ray diffraction spectra were recorded using SHIMADZU model XRD-7000 Maxima ( $\mathrm{Cu}-\mathrm{K} \alpha$ radiation source, $\lambda=$ $1.5418 \AA$ ) with scan rate $2 \%$ min. The chemical composition of the samples was obtained using X-ray fluorescence spectrometer, SHIMADZU model XRF-1800. The size and morphology of zeolite particles were determined from Scanning Electron Microscope (SEM) measurements which were performed using FEI-FEG INSPEC F50 instrument. The multipoint BET specific surface area $\left(\mathrm{S}_{\mathrm{BET}}\right)$, total pore volume $\left(\mathrm{V}_{\mathrm{p}}\right)$ and the sorption characteristic of samples were determined from $\mathrm{N}_{2}$ adsorption/ desorption isotherms that were measured using NOVA 2200e instrument. Total pore volume $\left(\mathrm{V}_{\mathrm{p}}\right)$ was calculated at a relative pressure close to unity. The reaction products were monitored using manual injection on a SHIMADZU model GC-17A gas chromatograph equipped with a carbowax $20 \mathrm{M}$ column (25 $\mathrm{m} \times 0.20 \mathrm{~mm}$ ID $\times 0.20 \mu \mathrm{m})$ and FID detector. Standard references of commercial products were injected to confirm the nature of reaction products. The analyses of reaction product (ethylene glycol with benzyl alcohol) were carried out at the following chromatographic conditions: detector and injector temperature $240{ }^{\circ} \mathrm{C}$, column temperature constant at $220^{\circ} \mathrm{C}$ and column flow rate of carrier gas $(\mathrm{He})$ was $0.8 \mathrm{~mL} / \mathrm{min}$. Retention times: peak at 4.74 min ethylene glycol, at 6.19 min benzyl alcohol, at 7.30 min 1,5-pentanediol (internal standard) at $14.93 \mathrm{~min}$ EGDBE and at $9.71 \mathrm{~min}$ EGMBE. The analyses of the reaction product (ethylene glycol with $t$-butanol) was carried out at the following chromatographic conditions: detector and injector temperature was set at $240{ }^{\circ} \mathrm{C}$. Temperature program was used with initial oven temperature of $\left(70^{\circ} \mathrm{C}, 5 \mathrm{~min}\right)$, temperature rate of $\left(30^{\circ} \mathrm{C} \mathrm{min}^{-1}\right)$, to a final oven temperature $\left(220^{\circ} \mathrm{C}\right.$, $5 \mathrm{~min}$ ). The column flow rate was $1.5 \mathrm{~mL} / \mathrm{min}$. Retentions times: peak at $12.73 \mathrm{~min}$ ethylene glycol, at $4.07 \mathrm{~min} t$-butanol, at $5.84 \mathrm{~min}$ 1-propanol (internal standard) and at $9.34 \mathrm{~min}$ EGMTE. The linearity of GC-FID response toward standard solutions of analysts was confirmed in the analysis range. The catalytic data was determined based on a single point calibration as a reference. The standard solutions and the catalytic reaction mixtures were injected in triplicate.

Synthesis of zeolite Beta: Zeolite Beta was synthesized from pure chemicals and crystallized from a hydrogel with the molar composition: $2.26 \mathrm{Na}_{2} \mathrm{O}: 1.04 \mathrm{~K}_{2} \mathrm{O}: 13.06$ (TEA) ${ }_{2} \mathrm{O}$ : $1.00 \mathrm{Al}_{2} \mathrm{O}_{3}: 52.9 \mathrm{SiO}_{2}: 795 \mathrm{H}_{2} \mathrm{O}$, following a literature procedure [38]. It was also synthesized from high silica raw kaolinite. In a typical procedure, kaolinite clay sample was dried at $110^{\circ} \mathrm{C}$ for $2 \mathrm{~h}$, and the particles $\leq 75 \mu \mathrm{m}$ were collected using a $75 \mu \mathrm{m}$ sieve. The kaolinite was transformed into metakaolinite via heating at $600{ }^{\circ} \mathrm{C}$ for $2 \mathrm{~h}$. Metakaolinite $(25 \mathrm{~g})$ was added to a sulfuric acid solution $(100 \mathrm{~mL}, 3.0 \mathrm{M})$ and the mixture was heated at $90^{\circ} \mathrm{C}$ for $2 \mathrm{~h}$ in a water bath shaker. The unreacted solid (dealuminated metakaolinite) was separated, washed with deionized water $(5 \times 200 \mathrm{~mL})$ and ethanol $(50 \mathrm{~mL})$ and dried at $110^{\circ} \mathrm{C}$ overnight. Dealuminated metakaolinite was then treated with sodium hydroxide solution $(50.0 \mathrm{~mL}, 4.0 \mathrm{M})$ in a polyethylene bottle at $90{ }^{\circ} \mathrm{C}$ for $2 \mathrm{~h}$, in a water bath shaker. The unreacted residue was separated and washed with deionized water $(30 \mathrm{~mL})$. The aluminosilicate solution and washing were combined and then neutralized by dropwise addition of conc. $\mathrm{H}_{2} \mathrm{SO}_{4}(98 \%)$, under continuous stirring. The white precipitate formed was separated, washed with deionized water $(5 \times 200 \mathrm{~mL})$ and ethanol $(30 \mathrm{~mL})$ and dried at $110^{\circ} \mathrm{C}$ overnight. The aluminosilicate solid $(4.00 \mathrm{~g})$ was gradually added with stirring to a solution containing: $\mathrm{NaCl}(0.240 \mathrm{~g}, 0.0041 \mathrm{~mol}), \mathrm{KCl}(0.190 \mathrm{~g}, 0.0025 \mathrm{~mol})$ and $\mathrm{NaOH}(0.045 \mathrm{~g}, 0.0011 \mathrm{~mol})$ in TEAOH solution (20 wt \%, $24.200 \mathrm{~g}, 0.033 \mathrm{~mol})$. The hydrogel formed was stirred till it was completely homogenized and then it was treated hydrothermally at $135^{\circ} \mathrm{C}$ for $20 \mathrm{~h}$, using Teflon-lined stainless steel autoclave. The reaction mixture was separated, washed with deionized water $(5 \times 10 \mathrm{~mL}$, till a pH of $10.5-11)$, ethanol $(5 \mathrm{~mL})$ and dried at $110^{\circ} \mathrm{C}$. The product was then calcined at $550^{\circ} \mathrm{C}$ for $6 \mathrm{~h}$. The acid form of zeolite Beta was obtained according to a literature procedure [17].

Synthesis of zeolite ZSM-5: Zeolite ZSM-5 was synthesized from pure chemicals and crystallized from a hydrogel with the molar composition: $79.0 \mathrm{Na}_{2} \mathrm{O}: 0.852$ (TPA) ${ }_{2} \mathrm{O}: 1.00 \mathrm{Al}_{2} \mathrm{O}_{3}: 42.7$ $\mathrm{SiO}_{2}$ : $2232 \mathrm{H}_{2} \mathrm{O}$, following a literature procedure [17]. It was also synthesized from high silica raw kaolinite according the following typical procedure:

A sample of raw kaolinite was treated with sulfuric acid and sodium hydroxide in the same way as described in the synthesis of zeolite Beta. Tetrapropylammonium bromide (TPABr, $3.20 \mathrm{~g}$ ) was added to alkaline filtrate and $\mathrm{pH}$ was adjusted at 10 by dropwise addition of conc. sulfuric acid (98\%). The mixture was stirred vigorously for $1 \mathrm{~h}$ and the hydrogel obtained was transferred into an autoclave and placed in an oven at $170{ }^{\circ} \mathrm{C}$ for two days. The solid product was filtered and washed with deionized water until the filtrate is sulfate free (tested by $\mathrm{BaCl}_{2}$ ). 
The zeolite was dried at $110^{\circ} \mathrm{C}$ for $1 \mathrm{~h}$ and then calcined at $550{ }^{\circ} \mathrm{C}$ for $6 \mathrm{~h}$. Zeolite H-ZSM-5 was obtained according to the literature procedure [17].

Catalytic etherification experiments: The etherification reaction was conducted by mixing the appropriate alcohols and the catalyst with no solvent. In a typical procedure, ethylene glycol (1.86 g, $30.0 \mathrm{mmol})$, benzyl alcohol (3.25 g, $30 \mathrm{mmol})$ and catalyst $(0.19 \mathrm{~g}, 10 \mathrm{wt} \%$ of ethylene glycol) were placed in a $25 \mathrm{~mL}$ round bottomed flask. The mixture was heated with stirring in an oil bath at $150{ }^{\circ} \mathrm{C}$ for $2 \mathrm{~h}$. The catalyst was filtered and washed with methanol $(3 \mathrm{~mL})$. The filtrate and washing were combined and dried over anhydrous sodium sulfate. Sodium sulfate was filtered and washed with methanol $(3 \mathrm{~mL})$. The filtrate and washing were combined and finally methanol was added till a volume of $10 \mathrm{~mL}$. The same procedure was adopted for the reaction of ethylene glycol with $t$-butanol except that the reaction was refluxed and 2-methoxyethanol was used for washing the catalyst and to complete the volume to $10 \mathrm{~mL}$.

\section{RESULTS AND DISCUSSION}

Synthesis of zeolites: The raw kaolinite used in this study is highly contaminated with quartz as evidenced by XRD. Accordingly, the method adopted here allows for complete removal of this major impurity. The first step in the synthesis involves thermal activation of kaolinite (heating at $600{ }^{\circ} \mathrm{C}$ for $2 \mathrm{~h}$ ) to form the metastable phase metakaolinite. The crystalline structure of kaolinite was confirmed by XRD spectra [17].

In the next step, metakaolinite was treated with sulfuric acid under control conditions of temperature and contact time to control the aluminum content of acid-leached metakaolinite. The acid-leaching process is important for removal of inorganic impurities, such as metal oxides including iron oxide (Table-1) [17]. In addition, dealumination of metakaolinite helps in the dissolution of silicate constituent of metakaolinite in alkaline treatment employed in the next step. Apart from reported acidleaching methods $[6,7,12-17]$, to control the dealumination process and to weaken the aluminosilicate structure to become more susceptible for alkaline treatment.

The effect of sulfuric acid concentration on $\mathrm{SiO}_{2} / \mathrm{Al}_{2} \mathrm{O}_{3}$ molar ratio, degree of dealumination, mass of dealuminated solid and mass of unreacted solid residue (after base treatment) was systematically investigated. As shown in Table-2 (Fig. 1), there is a significant increase in the $\mathrm{SiO}_{2} / \mathrm{Al}_{2} \mathrm{O}_{3}$ molar ratio and degree of dealumination (eqn. 1) with increasing the acid concentration from $1.0 \mathrm{M}$ to $3.0 \mathrm{M}$.

$$
\text { Dealumination }(\%)=\frac{\left[\left(\mathrm{Al}_{2} \mathrm{O}_{3} / \mathrm{SiO}_{2}\right)_{\mathrm{m}}-\left(\mathrm{Al}_{2} \mathrm{O}_{3} / \mathrm{SiO}_{2}\right)_{\mathrm{dm}}\right]}{\left[\left(\mathrm{Al}_{2} \mathrm{O}_{3} / \mathrm{SiO}_{2}\right)_{\mathrm{m}}\right]}
$$

where $\mathrm{m}=$ metakaolinite and $\mathrm{dm}=$ dealuminated metakaolinite .

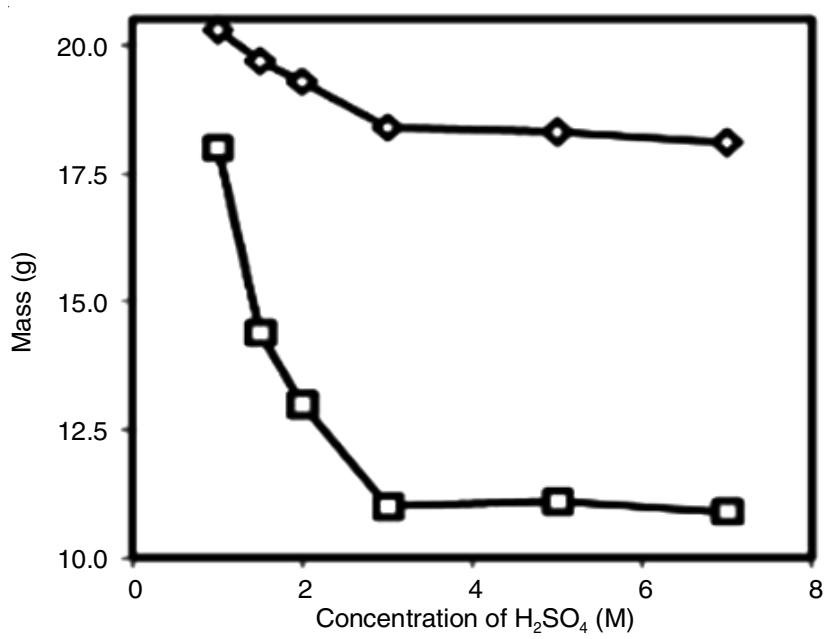

Fig. 1. Effect of sulfuric acid concentration on mass of dealuminated metakaolinite $(\diamond)$ and on mass of unreacted solid residue $(\square)$

\begin{tabular}{cccccc} 
TABLE-1 & \multicolumn{3}{c}{$\begin{array}{c}\text { CHEMICAL ANALYSIS (XRF) OF RAW KAOLINITE, ZEOLITE ZSM-5 AND ZEOLITE } \\
\text { BETA PREPARED FROM PURE CHEMICALS AND FROM RAW KAOLINITE }\end{array}$} \\
\hline Oxide & Raw kaollinite & $\begin{array}{c}\text { Zeolite ZSM-5 } \\
\text { (pure chemicals) }\end{array}$ & $\begin{array}{c}\text { Zeolite ZSM-5 } \\
\text { (raw kaolinite) }\end{array}$ & $\begin{array}{c}\text { Zeolite Beta } \\
\text { (pure chemicals) }\end{array}$ & $\begin{array}{c}\text { Zeolite Beta } \\
\text { (raw kaolinite) }\end{array}$ \\
\hline $\mathrm{SiO}_{2}$ & 62.36 & 90.89 & 91.11 & 88.91 & 83.18 \\
$\mathrm{Al}_{2} \mathrm{O}_{3}$ & 28.07 & 6.38 & 6.36 & 8.24 & 10.75 \\
$\mathrm{Na}_{2} \mathrm{O}$ & 0.19 & 2.58 & 2.13 & 2.43 & 1.07 \\
$\mathrm{~K}_{2} \mathrm{O}$ & 0.14 & 0.06 & 0.05 & 0.07 & 4.23 \\
$\mathrm{Fe}_{2} \mathrm{O}_{3}$ & 2.18 & 0.05 & 0.31 & 0.08 & 0.48 \\
$\mathrm{CaO}$ & 4.10 & 0.05 & 0.04 & 0.00 & 0.23 \\
Other oxides & 2.96 & 0.00 & 0.00 & & 0.06 \\
\hline
\end{tabular}

\begin{tabular}{|c|c|c|c|c|}
\hline \multicolumn{5}{|c|}{$\begin{array}{l}\text { TABLE-2 } \\
\text { EFFECT OF SULFURIC ACID CONCENTRATION ON THE MASS OF DEALUMINATED METAKAOLINITE, } \\
\mathrm{SiO}_{2} / \mathrm{Al}_{2} \mathrm{O}_{3} \text { MOLAR RATIO, \% DEALUMINATION AND MASS OF UNREACTED SOLID RESIDUE }\end{array}$} \\
\hline Conc. of $\mathrm{H}_{2} \mathrm{SO}_{4}(\mathrm{M})$ & $\begin{array}{l}{ }^{\mathrm{a}} \text { Mass of dealuminated } \\
\text { metakaolinite }(\mathrm{g})\end{array}$ & $\begin{array}{c}\mathrm{SiO}_{2} / \mathrm{Al}_{2} \mathrm{O}_{3} \text { in dealuminated } \\
\text { metakaolinite }\end{array}$ & Dealumination (\%) & $\begin{array}{l}{ }^{\mathrm{b}} \text { Mass of unreacted } \\
\text { solid residue }(\mathrm{g})\end{array}$ \\
\hline 1.0 & 20.0 & 8 & 53 & 18.0 \\
\hline 1.5 & 19.7 & 15 & 75 & 14.4 \\
\hline 2.0 & 19.4 & 23 & 84 & 13.0 \\
\hline 3.0 & 18.4 & 41 & 91 & 11.0 \\
\hline 5.0 & 18.2 & 47 & 92 & 11.1 \\
\hline 7.0 & 18.0 & 68 & 94 & 10.9 \\
\hline
\end{tabular}


It is worth noting that the effect of acid concentration on the above variables diminishes in the range 3.0-7.0 M. The enhanced reactivity of dealuminated metakaolinite toward alkali could be explained by the increase in surface area and pore volume caused by acid leaching. The correlation between acid concentration and $\mathrm{S}_{\mathrm{BET}}$ and $\mathrm{V}_{\mathrm{p}}$ of dealuminated metakaolinite is shown in Table-3. There is a significant increase in $\mathrm{S}_{\mathrm{BET}}$ as the acid concentration increases from 0.0 to $2.0 \mathrm{M}$. However, the effect of acid concentration diminishes as the concentration increases from 2.0 to $7.0 \mathrm{M}$. Careful control of the above conditions allows the maximum dissolution of silicate species and the complete exclusion of unreacted contaminants including quartz.

\section{TABLE-3}

EFFECT OF SULFURIC ACID CONCENTRATION ON $S_{\text {BET }}$ AND $V_{\mathrm{p}}$ OF DEALUMINATED METAKAOLINITE

\begin{tabular}{ccc}
\hline $\mathrm{H}_{2} \mathrm{SO}_{4}(\mathrm{M})$ & $\mathrm{S}_{\mathrm{BET}}\left(\mathrm{m}^{2} / \mathrm{g}\right)$ & $\mathrm{V}_{\mathrm{p}}\left(\mathrm{cm}^{3} / \mathrm{g}\right)$ \\
\hline 0.0 & 11 & 0.01 \\
1.0 & 56 & 0.03 \\
1.5 & 102 & 0.06 \\
2.0 & 112 & 0.06 \\
3.0 & 113 & 0.07 \\
5.0 & 117 & 0.07 \\
7.0 & 118 & 0.07 \\
\hline
\end{tabular}

The crystalline phases of both zeolite Beta and zeolite ZSM-5 (synthesized from raw kaolinite) were confirmed by X-ray diffraction analysis (Figs. 2 and 3). The XRD spectra of both zeolites are comparable with the spectra of corresponding samples prepared from pure chemicals and consistent with ICDD card No. 00-048-0074 and No. 00-037-0361 for zeolite Beta and zeolite ZSM-5, respectively.

The SEM micrographs of zeolite Beta and zeolite ZSM-5 (Fig. 4) showed the particles of spherical shapes with approxi-

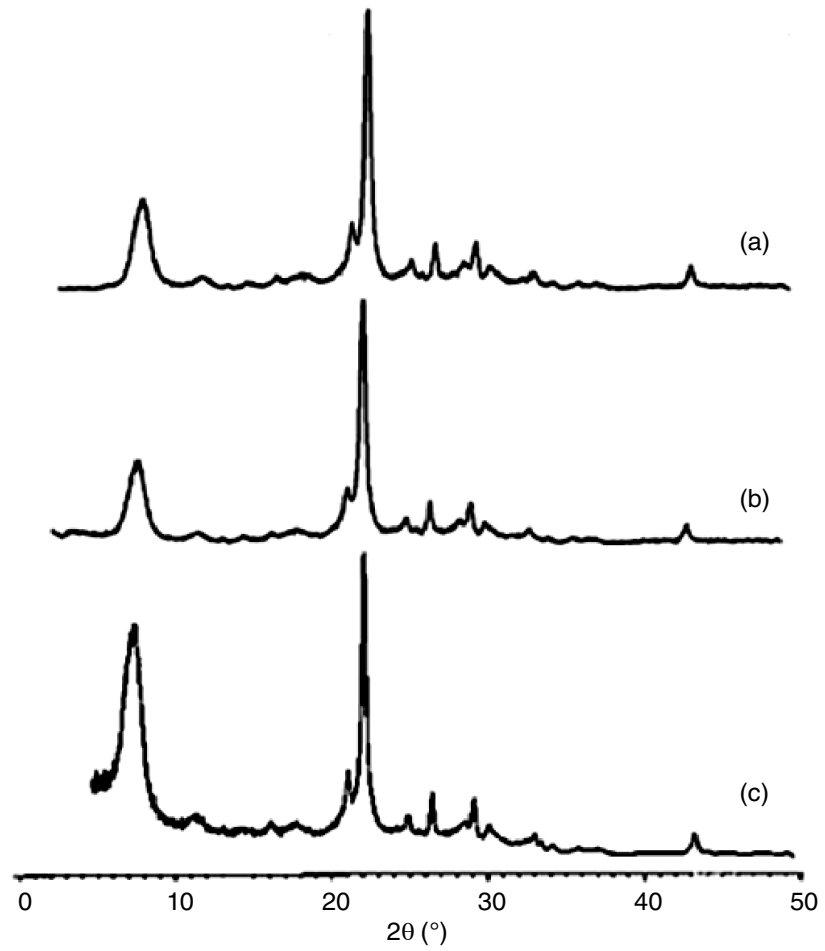

Fig. 2. XRD spectra of zeolite Beta prepared from (a) raw kaolinite, (b) pure chemicals and (c) a reference spectrum [ICDD card No. 00048-0074]

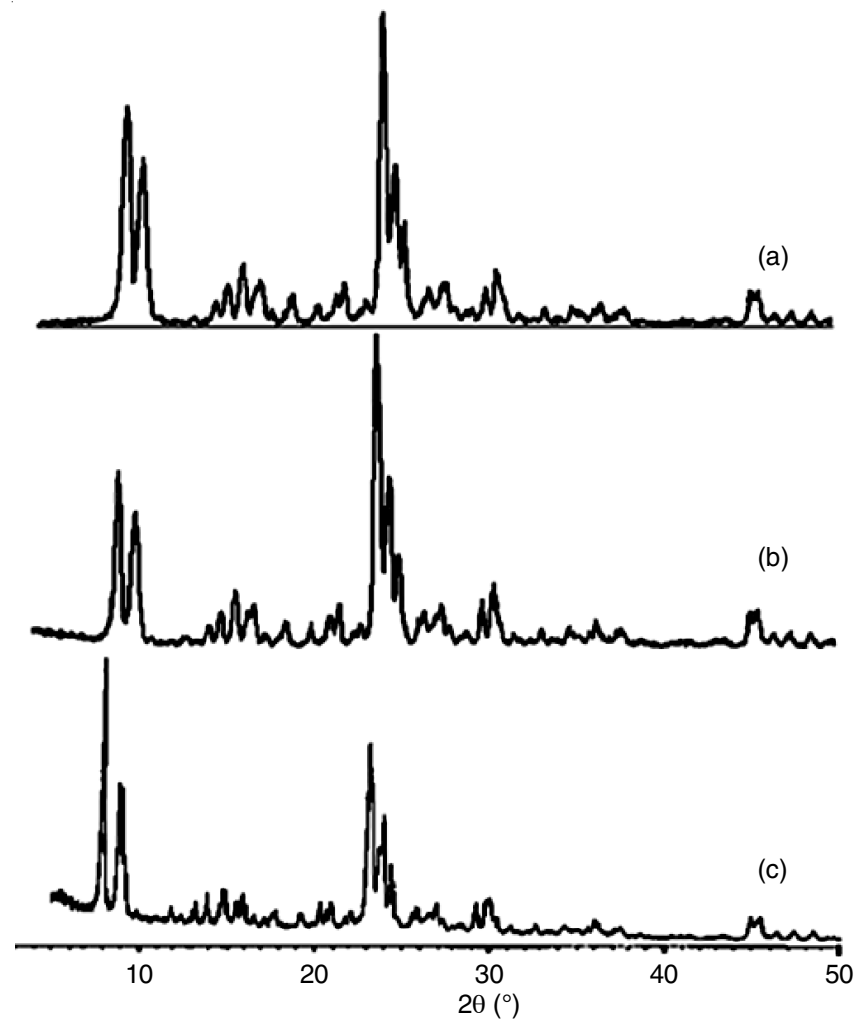

Fig. 3. XRD spectra of zeolite ZSM-5 prepared from (a) raw kaolinite, (b) pure chemicals and (c) a reference spectrum [ICDD card No. 00037-0361]

mate dimension of $300 \mathrm{~nm}$ for zeolite Beta, whereas, particles of zeolite ZSM-5 have rectangular prismatic shapes with approximate dimension of $280 \mathrm{~nm}$.

The $\mathrm{N}_{2}$-adsorption/desorption isotherms (Fig. 5) of both microporous zeolites belong to type I isotherm (IUPAC). The $\mathrm{S}_{\mathrm{BET}}\left(\mathrm{m}^{2} / \mathrm{g}\right)$ and $\mathrm{V}_{\mathrm{p}}\left(\mathrm{cm}^{3} / \mathrm{g}\right)$ values are: zeolite Beta/pure chemicals (513, 0.27), zeolite Beta/kaolinite (463,0.25), zeolite ZSM-5/ pure chemicals $(294,0.16)$ and zeolite ZSM-5/kaolinite (337, 0.19). A comparison between $\mathrm{SiO}_{2} / \mathrm{Al}_{2} \mathrm{O}_{3}$ molar ratio and $\mathrm{S}_{\mathrm{BET}}$ for the raw kaolinite used in this work $\left(3.8,11 \mathrm{~m}^{2} / \mathrm{g}\right)$ with that for purified kaolinite $\left(2.0,29 \mathrm{~m}^{2} / \mathrm{g}\right)$ [6] confirms the high content of quartz as evidenced by XRD.

Catalytic etherification of ethylene glycol: Liquid phase catalytic etherification of ethylene glycol with benzyl alcohol and with $t$-butanol were studied over samples of acid-activated zeolite Beta and zeolite ZSM-5, prepared from raw kaolinite. For comparison purposes, the reactions were conducted on samples of the above zeolites. All possible ether products from the reactions of ethylene glycol with benzyl alcohol and with $t$-butanol are presented in Figs. 6 and 7, respectively.

The results of the etherification reactions over acid-activated zeolites, either prepared from raw kaolinite or from pure chemicals, are shown in Table-4. Under these conditions, self-etherification of ethylene glycol was not observed. The percent yield of EGME was calculated based on eqn 2 .

$$
\text { Yield }(\%)=\frac{\mathrm{n}_{\mathrm{p}}}{\mathrm{n}_{\mathrm{r}}} \times 100
$$

where $n_{p}$ is the moles of EGME and $n_{r}$ is the initial moles of ethylene glycol. 

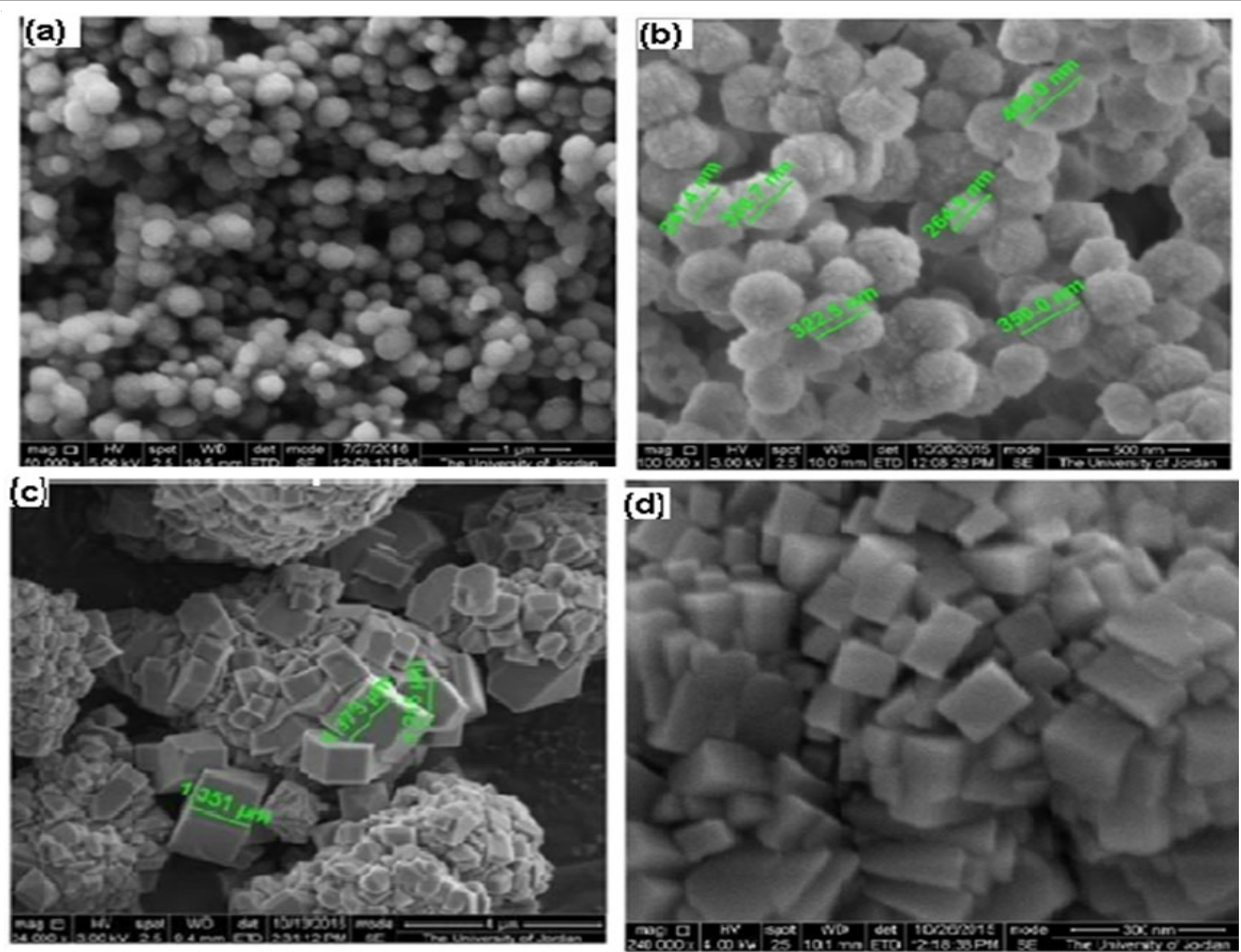

Fig. 4. SEM micrographs of (a) zeolite Beta prepared from pure chemicals, (b) zeolite Beta prepared from raw kaolinite, (c) zeolite ZSM-5 prepared from pure chemicals and (d) zeolite ZSM-5 prepared from raw kaolinite
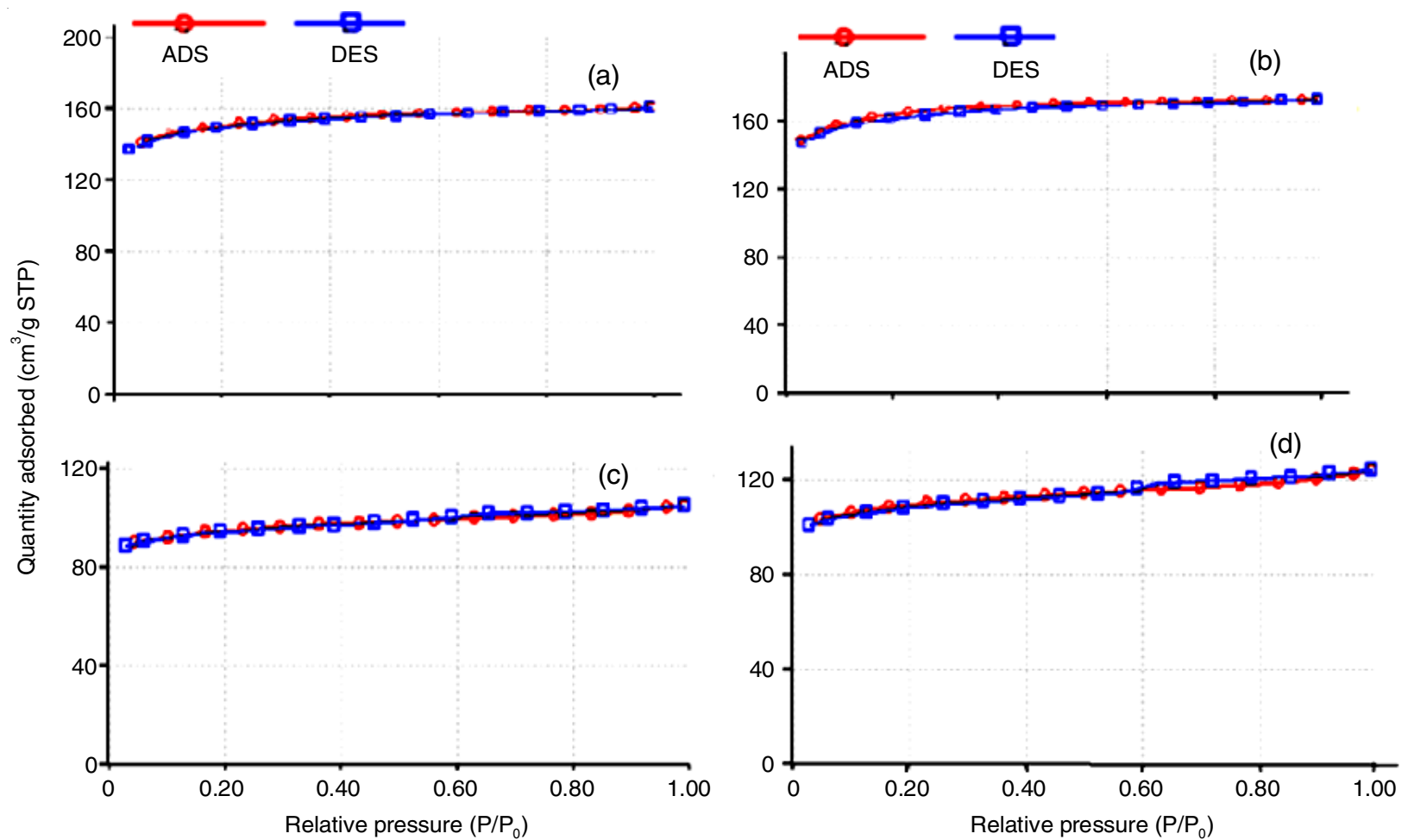

Fig. 5. $\mathrm{N}_{2}$ adsorption/desorption isotherms of (a) zeolite Beta prepared from pure chemicals, (b) zeolite Beta prepared from raw kaolinite, (c) zeolite ZSM-5 prepared from pure chemicals and (d) zeolite ZSM-5 prepared from raw kaolinite 
<smiles>OCCOCc1ccc(NO)cc1</smiles>

EGMBE<smiles>c1ccc(COCc2ccccc2)cc1</smiles>

Dibenzyl ether<smiles>OCCOCCOCc1ccccc1</smiles>

Fig. 6. Possible ether products for the etherification of ethylene glycol with benzyl alcohol<smiles>CC(C)(C)[CH+]OCCOC(C)(C)OCCOC(C)(C)OC(C)(C)OC(C)(C)OCCOC(C)(C)C</smiles>

Fig. 7. Possible ether products for the etherification of ethylene glycol with $t$-butanol

\begin{tabular}{|c|c|c|c|c|c|}
\hline \multicolumn{6}{|c|}{$\begin{array}{c}\text { TABLE-4 } \\
\text { YIELD (\%) OF EGMBE AND EGMTE OVER ZEOLITES H-ZSM-5 AND H-BETA } \\
\text { PREPARED FROM RAW KAOLINITE AND FROM PURE CHEMICALS }\end{array}$} \\
\hline & Blank & $\begin{array}{l}\text { H-zeolite Beta } \\
\text { (raw kaolinite) }\end{array}$ & $\begin{array}{c}\text { H-zeolite Beta } \\
\text { (pure chemicals) }\end{array}$ & $\begin{array}{c}\text { H-zeolite ZSM-5 } \\
\text { (raw kaolinite) }\end{array}$ & $\begin{array}{l}\text { H-zeolite ZSM-5 } \\
\text { (pure chemicals) }\end{array}$ \\
\hline EGMBE & 0.0 & 18 & 13 & 58 & 37 \\
\hline EGMTE & 0.0 & 0.53 & 0.53 & 5.0 & 2.2 \\
\hline
\end{tabular}

It is worth to mention that etherification reaction does not occur in the absence of zeolite catalysts or when using sodium form of the catalysts (other conditions were kept constant). A thorough inspection of the catalytic results for the reaction of ethylene glycol with benzyl alcohol or with $t$-butanol reveals the following observations about catalytic performance of zeolite H-Beta and zeolite H-ZSM-5.

(a) The reaction mixture of catalytic etherification reaction of ethylene glycol with benzyl alcohol over zeolite H-ZSM-5 (prepared from raw kaolinite or from pure chemicals) contained ethylene glycol, benzyl alcohol and EGMBE

(b) The reaction mixture of catalytic etherification reaction of ethylene glycol with benzyl alcohol over zeolite H-Beta (prepared from raw kaolinite or from pure chemicals) gave ethylene glycol, benzyl alcohol, EGMBE and EGDBE.

(c) The differences in catalytic performance between $\mathrm{H}$ ZSM-5 and H-Beta (Table-4) may be attributed to the difference in pore structure. With its large pore size, it seems that zeolite $\mathrm{H}$-Beta capable of stabilizing the transition state for the formation of EGDBE, while zeolite H-ZSM-5 is not expected to do so because of its smaller pore size. Similar observations were observed in the etherification of glycerol with benzyl alcohol over the above zeolites. Gonzalez-Arellano et al. [24] and Kubota et al. [25] reported that zeolite H-ZSM-5 is highly selective toward the production of glycerol monobenzyl ether. However, when mesoporous zeolite H-ZSM-5 was used, the formation of glycerol dibenzyl ether was enhanced.

(d) Zeolites H-ZSM-5 and H-Beta prepared from raw kaolinite gave higher yield of EGMBE than the corresponding zeolites prepared from pure chemicals. This might be attributed to the higher $S_{\mathrm{BET}}$ and $\mathrm{V}_{\mathrm{p}}$ of zeolites prepared from raw kaolinite compared with that prepared from pure chemicals. In addition, the enhancement in catalytic activity toward EGMBE could be attributed to the presence of trace amount of transition metal ions that usually found in raw kaolinite, such as iron.

(e) The catalytic activities of all the investigated zeolite systems toward the etherification of ethylene glycol with $t$-butanol were low. Although most of $t$-butanol was consumed during the reaction over zeolite $\mathrm{H}$-Beta but that was not reflected on the percent yield of EGMTE. This may be attributed to the formation of isobutene gas via dehydration of $t$-butanol. The loss of isobutene gas resulted in gradual reduction of the reaction volume to about half its initial value. Such volume reduction has not been observed in case of zeolite H-ZSM-5. Previous reports $[26,27]$ about catalytic etherification reaction of glycerol with $t$-butanol over zeolite $\mathrm{H}$-Beta, in closed system, reported good catalytic performance toward the formation of glycerol mono $t$-butyl ether and to a smaller extent the formation of glycerol di-t-butyl ether.

\section{Conclusion}

Pure phases of zeolite Beta and zeolite ZSM-5 with $\mathrm{SiO}_{2} /$ $\mathrm{Al}_{2} \mathrm{O}_{3}$ molar ratio lower than 25 were prepared from high silica raw kaolinite. Their structural and physical properties are comparable with the corresponding ones prepared from pure chemicals. The acid-activated forms, H-Beta and H-ZSM-5 show different catalytic activities in the etherification reactions of ethylene glycol with benzyl alcohol and with $t$-butanol, which could be attributed to the differences in pore structure. The study could be considered as a preliminary approach for the catalytic preparation of a family of hydroxy functionalized ethers. 


\section{ACKNOWLEDGEMENTS}

The authors gratefully acknowledge the financial support provided by the Deanship of Academic Research, The University of Jordan, Amman, Jordan.

\section{REFERENCES}

1. (a) J. Perez-Pariente, J.A. Martens and P.A. Jacobs, Zeolites, 8, 46 (1988);

https://doi.org/10.1016/S0144-2449(88)80029-0.

(b) R.L. Wadlinger, G.T. Kerr and E.J. Rosinski, Catalytic Composition of a Crystalline Zeolite, US Patent 3,308,069 (1967).

2. M.W. Kasture, P.S. Niphadkar, S.R. Kate, P.D. Godbole, K.R. Patil, G.M. Chaphekar and P.N. Joshi, Stud. Surf. Sci. Catal., 154, 3081 (2004); https://doi.org/10.1016/S0167-2991(04)80595-0.

3. Y.J. Lee, S.D. Kim, S.C. Byun, J.W. Park, Y.J. Jeong, Y.J. Kwon, H.O. Song and W. Kim, J. Cryst. Growth, 297, 138 (2006);

https://doi.org/10.1016/j.jcrysgro.2006.09.040.

4. A. Sagarzazu and G. Gonzalez, Mater. Chem. Phys., 138, 640 (2013); https://doi.org/10.1016/j.matchemphys.2012.12.033.

5. H.H. Murray, Clay Miner, 34, 39 (1999); https://doi.org/10.1180/000985599546055.

6. Y. Zhang, W. Gao and L. Cui, Stud. Surf. Sci. Catal., 170, 420 (2007); https://doi.org/10.1016/S0167-2991(07)80870-6.

7. A. Duan, G. Wan, Y. Zhang, Z. Zhao, G. Jiang and J. Liu, Catal. Today, 175, 485 (2011);

https://doi.org/10.1016/j.cattod.2011.03.044.

8. R.J. Argauer and G.R. Landolt, Crystalline Zeolite ZSM-5 and Method of preparing the Same. US Patent No. 3,702,886 (1972).

9. N. Kumar, V. Nieminen, K. Demirkan, T. Salmi, D. Yu. Murzin and E. Laine, Appl. Catal. A, 235, 113 (2002); https://doi.org/10.1016/S0926-860X(02)00258-2.

10. Q. Dai, S. Bai, X. Wang and G. Lu, J. Porous Mater, 21, 1041 (2014); https://doi.org/10.1007/s10934-014-9854-Z.

11. C. Liu, W. Gu, D. Kong and H. Guo, Micropor. Mesopor. Mater, 183, 30 (2014); https://doi.org/10.1016/j.micromeso.2013.08.037.

12. C.D. Madhusoodana, Y. Kameshima, A. Yasumori and K. Okada, Clay Sci., 11, 369 (2001)

13. C.D. Madhusoodana, R.N. Das, Y. Kameshima and K. Okada, J. Porous Mater, 12, 273 (2005); https://doi.org/10.1007/s10934-005-3125-y.

14. E. Vessally, M.D. Esrafili, Z. Alimadadi and M. Rouhani, Green Chem. Lett. Rev., 7, 119 (2014); https://doi.org/10.1080/17518253.2014.895865.

15. F. Pan, X. Lu, Y. Wang, S. Chen, T. Wang and Y. Yan, Mater. Lett., 115, 5 (2014); https://doi.org/10.1016/i.matlet.2013.10.007.

16. A.S. Kovo, O. Hernandez and S.M. Holmes, Mater. Chem., 19, 6207 (2009); https://doi.org/10.1039/b907554b.

17. A.F. Lafi, S.K. Matam and H.A. Hodali, Ind. Eng. Chem. Res., 54, 3754 (2015); https://doi.org/10.1021/ie505004k.

18. T. Tejero, C. Fité, M. Iborra, J.F. Izquierdo, F. Cunill and R. Bringué, Micropor. Mesopor. Mater., 117, 650 (2009); https://doi.org/10.1016/j.micromeso.2008.08.055.
19. E. Medina, R. Bringue, J. Tejero, M. Iborra and C. Fite, Appl. Catal. A, 374, 41 (2010); https://doi.org/10.1016/j.apcata.2009.11.024.

20. I. Hoek, T.A. Nijhuis, A.I. Stankiewicz and J.A. Moulijn, Appl. Catal. A, 266, 109 (2004); https://doi.org/10.1016/j.apcata.2004.02.005.

21. J.F. Knifton and P.E. Dai, One-Step Synthesis of Methyl t-Butyl ether from t-Butanol using $\beta$-zeolite catalysts Modified with Lithium Plus Rare Earths, US Patent 5,387,723 (1995).

22. S. Assabumrungrat, D. Wongwattanasate, V. Pavarajarn, P. Praserthdam, A. Arpornwichanop and S. Goto, Korean J. Chem. Eng., 21, 1139 (2004); https://doi.org/10.1007/BF02719485.

23. J.W. Kim, D.J. Kim, J.U. Han, M. Kang, J.M. Kim and J.E. Yie, Catal. Today, 87, 195 (2003); https://doi.org/10.1016/j.cattod.2003.10.006.

24. C. Gonzalez-Arellano, A. Grau-Atienza, E. Serrano, A.A. Romero, J. Garcia-Martinez and R. Luque, J. Mol. Catal. A-Chem., 406, 40 (2015); https://doi.org/10.1016/j.molcata.2015.05.011.

25. M. Kubota, A. Sakamoto, M. Komatsu, K. Maeno and A. Masuyama, J. Oleo Sci., 63, 1057 (2014); https://doi.org/10.5650/jos.ess13214.

26. N. Ozbay, N. Oktar, G. Dogu and T. Dogu, Top. Catal., 56, 1790 (2013); https://doi.org/10.1007/s11244-013-0116-0.

27. M.D. Gonzalez, P. Salagre, M. Linares, R. Garcia, D. Serrano and Y. Cesteros, Appl. Catal. A, 473, 75 (2014); https://doi.org/10.1016/j.apcata.2013.12.038.

28. B. Guruswamy and R. Arul, Lett. Drug Des. Discov., 10, 86 (2013); https://doi.org/10.2174/157018013804142492.

29. K. Huang, M. Ortiz-Marciales, W. Correa, E. Pomales and X.Y. López, J. Org. Chem., 74, 4195 (2009); https://doi.org/10.1021/j0900666r.

30. J.M. Bobbitt, A.L. Bartelson, W.F. Bailey, T.A. Hamlin and C.B. Kelly, J. Org. Chem., 79, 1055 (2014); https://doi.org/10.1021/j0402519m.

31. G.D. Yadav and S. Singh, Tetrahedron Lett., 55, 3979 (2014); https://doi.org/10.1016/j.tetlet.2014.05.017.

32. D.R. Billodeaux, T.J. Devon, J.M. Penney, D.L. Terrill, R.T. Hembre and J.L. Stavinoha, Production of Hydroxy Ether Hydrocarbons by Liquid Phase Hydrogenolysis of Cyclic Acetals or Cyclic Ketals, WO Patent 177,469 (2012).

33. H. Kotsuki, Y. Ushio, N. Yoshimura and M. Ochi, J. Org. Chem., 52, 2594 (1987); https://doi.org/10.1021/jo00388a049.

34. T. Yoshino, S. Inaba and Y. Ishido, Bull. Chem. Soc. Jpn., 46, 553 (1973); https://doi.org/10.1246/bcsj.46.553.

35. Y. Liu, S.K. Park, Y. Xiao and J. Chae, Org. Biomol. Chem., 12, 4747 (2014); https://doi.org/10.1039/c4ob00649f.

36. G.D. Yadav, S.O. Katole and A.K. Dalai, Appl. Catal. A, 477, 18 (2014); https://doi.org/10.1016/j.apcata.2014.02.017.

37. V.I. Parvulescu, S.M. Coman, N.C. Candu, J. El Haskouri, D. Beltran and P. Amoros, J. Mater. Sci., 44, 6693 (2009); https://doi.org/10.1007/s10853-009-3599-0.

38. M.A. Camblor and J. Perez-pariente, Zeolites, 11, 202 (1991); https://doi.org/10.1016/S0144-2449(05)80220-9. 